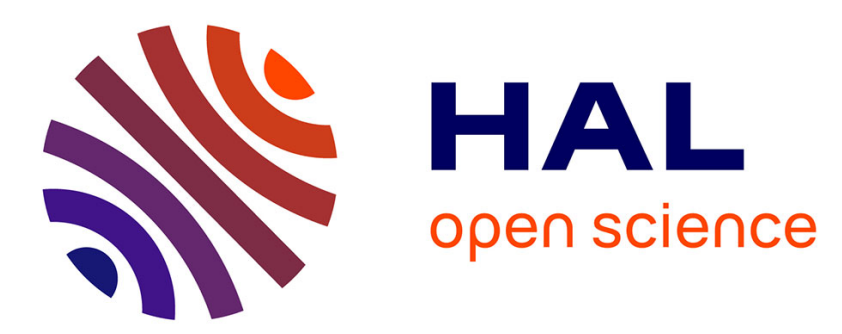

\title{
Pulsed laser deposited alumina thin films
}

Rémi Boidin, Tomáš Halenkovič, Virginie Nazabal, Ludvík Beneš, Petr Němec

\section{To cite this version:}

Rémi Boidin, Tomáš Halenkovič, Virginie Nazabal, Ludvík Beně̌, Petr Němec. Pulsed laser deposited alumina thin films. Ceramics International, 2016, 42 (1, Part B), pp.1177-1182. 10.1016/j.ceramint.2015.09.048 . hal-01202033

\section{HAL Id: hal-01202033 \\ https://hal-univ-rennes1.archives-ouvertes.fr/hal-01202033}

Submitted on 7 Jan 2016

HAL is a multi-disciplinary open access archive for the deposit and dissemination of scientific research documents, whether they are published or not. The documents may come from teaching and research institutions in France or abroad, or from public or private research centers.
L'archive ouverte pluridisciplinaire HAL, est destinée au dépôt et à la diffusion de documents scientifiques de niveau recherche, publiés ou non, émanant des établissements d'enseignement et de recherche français ou étrangers, des laboratoires publics ou privés. 
Pulsed laser deposited alumina thin films

Rémi Boidin, ${ }^{\ddagger}$ Tomáš Halenkovič,${ }^{\ddagger}$ Virginie Nazabal, ${ }^{\S,}$ Ludvík Beneš, ${ }^{\natural}$ and Petr Němec ${ }^{\ddagger}$,

${ }^{*}$ Department of Graphic Arts and Photophysics, Faculty of Chemical Technology, University of Pardubice, 53210 Pardubice, Czech Republic

$\S$ Institut des sciences chimiques de Rennes, UMR CNRS 6226, Equipe Verres et Céramiques, Université de Rennes 1, 35042 Rennes, France

" Joint Laboratory of Solid State Chemistry of the Institute of Macromolecular Chemistry AS CR, v.v.i. and University of Pardubice, 53210 Pardubice, Czech Republic

* Author to whom correspondence should be addressed. E-mail: petr.nemec@upce.cz; Tel.: +420466038502; Fax: +420466037068 


\begin{abstract}
Thin films of amorphous alumina were fabricated using pulsed laser deposition. Topography, structural, and optical properties of alumina films were investigated depending on process parameters, specifically deposition time under vacuum and partial pressure of argon. Deposited films present good uniformity with RMS roughness ranging from 0.35 to $2.50 \mathrm{~nm}$. Alumina films with thickness lower than $40 \mathrm{~nm}$ deposited under vacuum present a non-negligible void content that induces a decrease of the effective refractive index of the layers. Furthermore, introduction of argon gas (at $5 \times 10^{-4}$ and $5 \times 10^{-2}$ mbar) during the deposition process induces grainy structure of the thin films documented by an increase of RMS roughness from 0.35 to $1.5 \mathrm{~nm}$. A decrease of the alumina layers' refractive index is observed in the $300-7500 \mathrm{~nm}$ spectral range when increasing Ar pressure.
\end{abstract}

Keywords: pulsed laser deposition; alumina; amorphous; thin films; refractive index 


\section{Introduction}

Alumina $\left(\mathrm{Al}_{2} \mathrm{O}_{3}\right)$ is a highly insulating ceramic material which can be found in the form of several different crystalline phases including $\alpha$ and $\gamma-\mathrm{Al}_{2} \mathrm{O}_{3}$. Among them, corundum $\left(\alpha-\mathrm{Al}_{2} \mathrm{O}_{3}\right)$ with rhombohedral structure is the most stable. The $\alpha-\mathrm{Al}_{2} \mathrm{O}_{3}$ single crystal, commonly used in optics and electronics, is also known as sapphire. Alumina can also be found in the amorphous state $\left(\mathrm{a}-\mathrm{Al}_{2} \mathrm{O}_{3}\right) . \mathrm{Al}_{2} \mathrm{O}_{3}$ exhibits many interesting features including high optical transparency, chemical, and mechanical stability even at the temperatures up to $1000^{\circ} \mathrm{C}$ related to its high melting point, corrosion resistance, and high hardness [1-5]. Due to the mentioned properties, alumina finds a wide range of applications in the field of wear-resistant and corrosion protective coatings [6], optoelectronics, catalysis, sensors, and tribology [7, 8]. In industry, chemical vapor deposition (CVD) processes are often applied for crystallized $\mathrm{Al}_{2} \mathrm{O}_{3}$ coatings to diverse substrates including those with complex geometries. This method may have some drawback as related, for instance, to thermal expansion coefficients contrast between substrate and film deposited at high temperature, to a lesser extent in case of plasma enhanced CVD $[9,10]$. On the other hand, physical vapor deposition techniques can be operated at significantly lower substrate temperatures compared to CVD and can be used especially for amorphous $\mathrm{Al}_{2} \mathrm{O}_{3}$ coatings.

Amorphous $\mathrm{Al}_{2} \mathrm{O}_{3}$ is considered as one of the potential materials for replacing $\mathrm{SiO}_{2}$ in dielectric applications, since it exhibits higher bandgap and dielectric constant ( 9.9 vs. $9 \mathrm{eV}$ and $\sim 10$ vs. 3.9, respectively) [11-13]. Various deposition techniques such as magnetron sputtering $[1,3,4,6,8,12-19]$, electron beam evaporation [20-22], and pulsed laser deposition (PLD) [7, 23-25] can be used for the preparation of both crystalline and amorphous alumina thin films. 
PLD seems to be generally interesting due to its simplicity and stoichiometric transfer of target material towards the substrate in case of appropriate choice of ablation laser wavelength and absorbing target material. This technique also enables to deposit hard and dense films without additional substrate heating usually required in some other PVD techniques [26]. It is difficult to influence and control the growth of an $\mathrm{Al}_{2} \mathrm{O}_{3}$ thin film on a substrate, especially at low temperature; thus, it is motivating to explore the effect of PLD process parameters on the morphology, topography and optical properties of very thin films.

The influence of background pressure on PLD films growth is mainly studied in case of oxygen and nitrogen gas devoted to oxide and nitride films while argon pressure effect is less studied. Yahiaoui et al. have already shown that the presence of oxygen in the deposition chamber changes the shape of plasma plume during the plasma creation in PLD process [5]. Different plasma shape can influence the growth rate and the morphology of deposited films connected also with the changes in optical properties [24-26]. According to Gottmann et al., the decrease of refractive index, related to the creation of porous and columnar films of alumina and zirconia at oxygen pressure of about 0.2 mbar, can be observed [23]. Furthermore, the creation of grainy structure or nanorods at pressure below 0.1 mbar may occur for some other systems such as $\mathrm{ZnO}$ [27]. The formation of bilayers by changing the background pressure was reported in case of $\mathrm{CeO}_{2}$ PLD films with 10-40 nm nanoparticles for pressure of $\sim 0.2 \mathrm{mbar}$ [28]. To our best knowledge, no experiments exploring the influence of argon atmosphere on the growth of amorphous alumina PLD films have been reported yet. Introduction of Ar pressure should lead to an increase of the particle collisions probability, affecting the shape of plasma plume, and thus could change the film growth mechanism. 
The aim of this work was to produce amorphous alumina thin films by PLD (using vacuum or argon gas) and to characterize fabricated films with the final goal to integrate such layers into photonics heterostructures. Surface quality, structural, and optical properties of as-deposited alumina films were investigated depending on the PLD process parameters.

\section{Experimental procedures}

Commercial polycrystalline alumina target of $4 \mathrm{~N}$ purity was ablated using $\mathrm{KrF}$ excimer laser (LAMBDA PHYSIK COMPex 102) with the following parameters: wavelength of $248 \mathrm{~nm}$, output energy of $280 \mathrm{~mJ}$ per pulse, energy fluency of $\sim 4.3 \mathrm{~J} . \mathrm{cm}^{-2}$ and pulse duration of $30 \mathrm{~ns}$. A polycrystalline target was selected instead of single crystal target even if single crystalline target with high density is known to be useful for reducing droplet formation. On the other hand, single crystalline target will be insufficient for $\mathrm{KrF}$ laser pulses optical absorption for wide bandgap insulators such as $\mathrm{Al}_{2} \mathrm{O}_{3}$.

Laser pulses were directed on the target at the repetition rate of $20 \mathrm{~Hz}$. Silicon (100) and microscopic glasses (soda-lime float glass from Knittel, Braunschweig, Germany) were used as substrates for PLD; they were positioned parallel to the target surface at the target-to-substrate distance of $5 \mathrm{~cm}$. To obtain films of suitable quality from the viewpoint of uniformity in thickness, off-axis PLD technique combining rotating substrates and targets was used. The processing gas in the chamber was argon at the pressure of $5 \times 10^{-4}$ or $5 \times 10^{-2}$ mbar. Roughness and optical properties of deposited films were compared with those deposited under vacuum $\left(4.5 \times 10^{-6} \mathrm{mbar}\right)$. All the depositions were performed at room temperature. We note that we do not expect significant changes of the substrate temperature during the depositions. 
Optical properties and thicknesses of deposited alumina films were obtained from the analysis of variable spectroscopic ellipsometry (VASE) data measured using two ellipsometers: a rotating analyzer ellipsometer measuring in UV-Vis-NIR $(300-2300 \mathrm{~nm})$ and a rotating compensator ellipsometer working in mid-IR $(\sim 1.7-33 \mu \mathrm{m})$ (both J. A. Woollam Co., Inc., Lincoln, NE, USA). The VASE measurements parameters are as follows: angles of incidence of $65^{\circ}, 70^{\circ}$ and $75^{\circ}$, resolution of UV-Vis-NIR ellipsometer of $20 \mathrm{~nm}$, resolution of the mid-IR ellipsometer of $16 \mathrm{~cm}^{-}$ 1.

In the visible-NIR part of electromagnetic spectra, Cauchy model $n=A+B / \lambda^{2}+C / \lambda^{4}$, with Urbach absorption tail, $k=A_{k} e^{B k[E-E 0]}$, seems to be suitable since it appropriately describes the normal dispersion of transparent materials in this region [2]. Two overlapping Gaussian oscillators with central energy of $\sim 0.08$ and $\sim 0.03 \mathrm{eV}$ were then added in the mid-IR region. This approach of ellipsometry mid-IR data modelling is in a good agreement with Thompson et al., where the central energy of Gaussians was $\sim 0.08$ and $\sim 0.04 \mathrm{eV}$, respectively [29]. Furthermore, Bruggeman effective medium approximation (BEMA) had to be employed for the determination of optical properties of layers with small thickness. This approximation assumes that a host material dielectric function is equal to the final effective complex dielectric function. By choosing depolarization factor value of $1 / 3$ one can predict that one material (e.g. voids) is incorporated as small spheres within the host material [29-31].

Morphology of the alumina films was studied by an atomic force microscope (Solver-Pro N, NT-MTD) in semi-contact mode with a scanned area of $10 \mu \mathrm{m} \times 10 \mu \mathrm{m}$ or $5 \mu \mathrm{m} \times 5 \mu \mathrm{m}$.

X-ray diffraction (XRD) data were obtained with a D8-Advance diffractometer (Bruker, AXS) with Bragg-Brentano $\theta-\theta$ geometry $(40 \mathrm{kV}, 40 \mathrm{~mA})$ using $\mathrm{Cu} \mathrm{K} \alpha$ radiation with secondary 
graphite monochromator. The diffraction angles were measured at room temperature from 5 to $65^{\circ}(2 \theta)$ in $0.02^{\circ}$ steps with a counting time of $5 \mathrm{~s}$ per step.

\section{Results and discussion}

Amorphous character of films was confirmed by XRD (Fig. 1). Films were deposited on silicon and their thicknesses were large enough for this technique (more than $100 \mathrm{~nm}$ ).

The first objective was to study the evolution of the films' properties deposited under vacuum, depending on their thicknesses. All the films were fabricated under identical experimental conditions except the time of deposition that was varying from 30 to 630 seconds. The thicknesses of fabricated alumina films are between 8.5 and $106 \mathrm{~nm}$, as results from VASE data analysis. AFM scans were performed $(10 \times 10 \mu \mathrm{m}$ area $)$ and RMS roughness of thin films deposited on silicon substrates was typically comprised between 0.40 and $2.50 \mathrm{~nm}$ indicating their acceptable smoothness. RMS roughness of single crystalline silicon wafer (100) substrates was found to be $\sim 0.1 \mathrm{~nm}$.

BEMA model was employed for the determination of optical properties of alumina films with thickness lower than $40 \mathrm{~nm}$. In the case of studied materials, the applicability of BEMA model for the analysis of VASE data is confirmed by low value of mean square errors (typically bellow 2). Figure 2 represents the evolution of thin films characteristics (refractive index, effective refractive index, voids content) obtained by ellipsometry. Refractive index of alumina films at $1.55 \mu \mathrm{m}$ varies from 1.61 to 1.68 . The effective refractive index is inversely proportional to the void content in the films. The percentage of voids becomes negligible for films with thickness above $40 \mathrm{~nm}$. Indeed, the effective refractive index tends to reach alumina refractive index for 
films thicker than $\sim 40 \mathrm{~nm}$ (Fig. 2). To conclude, effective refractive index and alumina refractive index are equal when the voids content is negligible, indicating that films became homogenous and continuous for thicknesses larger than $40 \mathrm{~nm}$.

Following thermodynamic approach to determine growth modes of thin films close to equilibrium [32], the deposited material will tend to cover the entire surface of the substrate if the adhesion energy is sufficient. In other words, the material will be able to wet the substrate, and the growth will be two-dimensional according to Frank-Van der Merwe model. Each unfinished layer tends to complete before a new layer starts to grow. This mode of growth is promoted when the binding energy between the deposited atoms is less strong than or equal to that between the thin film and the substrate. In the other case, the growth of material on substrate will be controlled by minimization of the material surface. It will wet the substrate surface partly and the growth will be three-dimensional (or Volmer-Weber growth mode), on which small nuclei are formed on the substrate. The seeds will grow to form islands which then will coalesce to give a thin continuous layer. This mode of growth is usually promoted when the atoms forming the deposited layer are more strongly bound to each other than with the substrate as is the case for the growth of metal on insulating or on contaminated substrates. Finally, one can also observe a transition from 2D to 3D growth mode according to Stransky-Krastanov.

Nevertheless, the growing PLD film is not in thermodynamic equilibrium and kinetic effects have also to be considered as the high super-saturation of the vapor leads to a large nucleation rate. The kinetics of the film growth process is generally determined by the nature of the deposited materials, the quality of the original surface of the substrate, the physical environment for film growth (i.e. deposition technique) and the experimental conditions. The kinetics processes involved in the growth of thin film from the vapor phase concern main factors as the surface diffusion, the nucleation and growth of seeds. The morphology of the surface depends on 
the competition between these various kinetic factors. In particular, if defects such as steps are present on the substrate, the deposited atoms will be preferentially captured by them (their bonding to the substrate is stronger on defects). In stepflow growth mode, the atoms quickly reach the energetically favorable sites on the edge of the steps before they had time to interact. Since diffusion is a thermally activated process, growth by flowstep will take place preferentially at high temperature and relatively low growth rates. When the surface diffusion of adatoms is lower, the atoms' accumulation in the steps is starting to be high and these atoms are free to interact to form two-dimensional metastable seeds. If seeds can be permanent, they will significantly alter the growth kinetics by providing energetically favorable sites for the incorporation of incident atoms. Depending on the characteristics of diffusion and bonding of atoms, the two-dimensional growth can be preserved or, conversely, the formation of threedimensional islands will occur. Finally, a statistical growth dominates when mobility of atoms on the surface is almost nil as each atom sticks where it arrives on surface. Under uniform random incident atoms flow, the uniformity of the surface decreases exponentially with the thickness of the deposited layer. To summarize, two extreme growth modes can be distinguished, that is, layer-by-layer growth and multilayer growth. In our case, to obtain a layer-by-layer growth mode for $\mathrm{Al}_{2} \mathrm{O}_{3}$ amorphous thin film, a steady interlayer mass transport must be present. Atoms deposited on top of a growing seeds or even island should reach its edge and diffuse to allow the completion of the lower layer. To reduce the thickness of the continuous $\mathrm{Al}_{2} \mathrm{O}_{3}$ layer presenting suitable optical properties (of $\sim 40 \mathrm{~nm}$ ), further PLD experiments will involve a study of substrate temperature influence to increase the mobility of the incident atoms on substrate to promote coalescence of the film, while avoiding the formation of a polycrystalline film.

The gas pressure introduced into PLD chamber during film deposition affects the kinetic energy of the ablated particles arriving at the substrate. Consequently, their kinetic energy can be 
varied from high initial energy in vacuum to low energies resulting from thermalization at sufficiently high pressure. The pressure range can be used to modify thin film growth as the diffusivity and both the absorption and desorption probability of the energetic particles at the film surface can be modified. In this frame, the influence of the argon background atmosphere was also investigated. Two pressures of Ar, specifically $5 \times 10^{-4}$ and $5 \times 10^{-2}$ mbar were introduced into the deposition chamber. For these experiments, Ar pressure of $5 \times 10^{-2} \mathrm{mbar}$ was the limit value of used set-up enabling reasonable control/stability of the deposition process. Films were ablated at constant deposition time of 630 seconds enabling reliable comparison of structural and optical properties. According the RMS roughness values obtained from AFM measurements $(5 \times 5 \mu \mathrm{m}$ scans), all the films exhibit relatively good smoothness (typically between 0.35 and $1.5 \mathrm{~nm}$ ). Despite of this, AFM images (Fig. 3) revealed the difference in morphology of deposited films caused by the presence of argon in the deposition chamber. Grainy textures of alumina films can be observed when partial pressure of Ar is $5 \times 10^{-2} \mathrm{mbar}$ (Fig. 3c). RMS roughness of these films was $\sim 1.5 \mathrm{~nm}$. For comparison, RMS roughness values of $\sim 0.5$ and $\sim 0.35$ were obtained for films deposited at pressure of $5 \times 10^{-4}$ mbar of Ar and under the vacuum, respectively.

According VASE measurements, different film thicknesses were determined indicating the change in growth rate, in the range of $\sim 1.6 \AA / \mathrm{s}$ for films deposited under vacuum to $\sim 1.8 \AA / \mathrm{s}$ for the films deposited at $5 \times 10^{-2}$ mbar of Ar. Thicknesses of the films deposited under partial pressure of $5 \times 10^{-4}$ mbar of Ar for 630 seconds were comparable with those deposited under vacuum giving roughly value of about $100 \mathrm{~nm}$. At low background pressures (typically $0.001-$ 0.01 mbar), interaction between the ablation plume and the gas creates scattering and broadening of the angular distribution of the plume and a reduction of the ablated particles density deposited on a substrate located in front of the target can be expected [28]. The pressure of $5 \times 10^{-4} \mathrm{mbar}$ of Ar was probably enough low not to be strongly influenced by gas-plume interaction. For higher 
pressure, the kinetic energy of the initial ablation plume is thermalized and at sufficiently high pressures, the ablated material can be transported toward the substrate via diffusion. The deposition rate was unpredictably little bit increased when the pressure of $\operatorname{Ar}$ of $5 \times 10^{-2} \mathrm{mbar}$ was introduced into the deposition chamber; this observation needs further analysis.

Refractive index of alumina layers deposited in Ar atmosphere with pressure of $5 \times 10^{-4} \mathrm{mbar}$ is comparable with those deposited under vacuum giving values of about 1.65 at wavelength of $1.55 \mu \mathrm{m}$. Furthermore, films deposited under background atmosphere of Ar with pressure of $5 \times 10^{-2}$ mbar have refractive index about 1.59 at the same wavelength indicating lower films' densities. Anyway, all refractive indices are lower than tabulated ones referred by Palik (synthetic corundum) with value of 1.74 but comparable with those published by Kischkat et al. (sputtered films - Al target, pressure of Ar of 0.6 Pa, flux of oxygen of 2.0 SCCM, sputter power of $200 \mathrm{~W}$, deposition rate $\sim 1 \mathrm{~nm}$ per minute) $[33,34]$. Refractive index spectral dependences of PLD films covering UV-Vis-NIR-mid-IR range are given in Fig. 4. It is worthy to note that the refractive index spectral dependence reported by Kischkat et al. [33] is very close to PLD films prepared under vacuum.

\section{Conclusions}

$\mathrm{Al}_{2} \mathrm{O}_{3}$ amorphous thin films were deposited by PLD employing UV excimer laser. Since alumina has a high potential in the field of optics as dielectric material, great emphasis is placed on the optimization of deposition process of this material. As observed in this work, despite a good smoothness a non-negligible void content is present when films with thickness lower than $40 \mathrm{~nm}$ are deposited. The presence of these voids induces a decrease of effective refractive index of the film. 
As shown in the other part of experiments, background atmosphere of argon can rapidly influence morphology and optical properties of alumina films. When an Ar partial pressure of $5 \times 10^{-2}$ mbar is introduced into the deposition chamber, grainy textures and a clear decrease of the refractive index are observed.

\section{Acknowledgements}

Czech Science Foundation (Project No. 15-02634S) and Ministry of Education, Youth, and Sports of the Czech Republic (Project CZ.1.07/2.3.00/30.0058 "Development of Research Teams at the University of Pardubice“) financially supported this work. Authors thank Dr. J. Gutwirth for his help with experiments under Ar atmosphere. 


\section{References}

[1] V. Edlmayr, M. Moser, C. Walter, C. Mitterer, Thermal stability of sputtered $\mathrm{Al}_{2} \mathrm{O}_{3}$ coatings, Surface \& Coatings Technology 204 (9-10) (2010) 1576-1581.

[2] J. Houska, J. Blazek, J. Rezek, S. Proksova, Overview of optical properties of $\mathrm{Al}_{2} \mathrm{O}_{3}$ films prepared by various techniques, Thin Solid Films 520 (16) (2012) 5405-5408.

[3] J.M. Schneider, W.D. Sproul, A. Matthews, Phase formation and mechanical properties of alumina coatings prepared at substrate temperatures less than 500 degrees $\mathrm{C}$ by ionized and conventional sputtering, Surface \& Coatings Technology 94-5 (1-3) (1997) 179-183.

[4] J.M. Schneider, W.D. Sproul, A. Matthews, Reactive ionized magnetron sputtering of crystalline alumina coatings, Surface \& Coatings Technology 98 (1-3) (1998) 1473-1476.

[5] K. Yahiaoui, S. Abdelli-Messaci, S. Messaoud-Aberkane, T. Kerdja, H. Kellou, Emission study of alumina plasma produced by a KrF laser, Spectrochimica Acta Part B-Atomic Spectroscopy 93 (2014) 20-27.

[6] R. Cremer, M. Witthaut, D. Neuschutz, G. Erkens, T. Leyendecker, M. Feldhege, Comparative characterization of alumina coatings deposited by RF, DC and pulsed reactive magnetron sputtering, Surface \& Coatings Technology 120 (1999) 213-218.

[7] G. Balakrishnan, P. Kuppusami, S.T. Sundari, R. Thirumurugesan, V. Ganesan, E. Mohandas, D. Sastikumar, Structural and optical properties of gamma-alumina thin films prepared by pulsed laser deposition, Thin Solid Films 518 (14) (2010) 3898-3902.

[8] J.L. Wang, Y.H. Yu, S.C. Lee, Y.W. Chung, Tribological and optical properties of crystalline and amorphous alumina thin films grown by low-temperature reactive magnetron sputterdeposition, Surface \& Coatings Technology 146 (2001) 189-194. 
[9] R. Funk, H. Schachner, C. Triquet, M. Kornmann, B. Lux, Coating of cemented carbide cutting tools with alumina by chemical vapor-deposition, J. Electrochem. Soc. 123 (2) (1976) 285-289.

[10] M. Fallqvist, S. Ruppi, M. Olsson, M. Ottosson, T.M. Grehk, Nucleation and growth of CVD alpha- $\mathrm{Al}_{2} \mathrm{O}_{3}$ on $\mathrm{Ti}_{\mathrm{x}} \mathrm{O}_{\mathrm{y}}$ template, Surface \& Coatings Technology 207 (2012) 254-261. [11] P. Katiyar, C. Jin, R.J. Narayan, Electrical properties of amorphous aluminum oxide thin films, Acta Materialia 53 (9) (2005) 2617-2622.

[12] S. Prasanna, R.G. Mohan, S. Jayakumar, M.D. Kannan, V. Ganesan, Dielectric properties of DC reactive magnetron sputtered $\mathrm{Al}_{2} \mathrm{O}_{3}$ thin films, Thin Solid Films 520 (7) (2012) 2689-2694. [13] M. Voigt, M. Sokolowski, Electrical properties of thin rf sputtered aluminum oxide films, Mater. Sci. Eng. B-Solid State Mater. Adv. Technol. 109 (1-3) (2004) 99-103.

[14] R. Cremer, K. Reichert, D. Neuschutz, G. Erkens, I. Leyendecker, Sputter deposition of crystalline alumina coatings, Surface \& Coatings Technology 163 (2003) 157-163.

[15] W.H. Ha, M.H. Choo, S. Im, Electrical properties of $\mathrm{Al}_{2} \mathrm{O}_{3}$ film deposited at low temperatures, J. Non-Cryst. Solids 303 (1) (2002) 78-82.

[16] A. Khanna, D.G. Bhat, Nanocrystalline gamma alumina coatings by inverted cylindrical magnetron sputtering, Surface \& Coatings Technology 201 (1-2) (2006) 168-173.

[17] J. Musil, J. Blazek, P. Zeman, S. Proksova, M. Sasek, R. Cerstvy, Thermal stability of alumina thin films containing gamma- $\mathrm{Al}_{2} \mathrm{O}_{3}$ phase prepared by reactive magnetron sputtering, Appl. Surf. Sci. 257 (3) (2010) 1058-1062.

[18] B.G. Segda, M. Jacquet, J.P. Besse, Elaboration, characterization and dielectric properties study of amorphous alumina thin films deposited by r.f. magnetron sputtering, Vacuum 62 (1) (2001) 27-38. 
[19] O. Zywitzki, G. Hoetzsch, Influence of coating parameters on the structure and properties of $\mathrm{Al}_{2} \mathrm{O}_{3}$ layers reactively deposited by means of pulsed magnetron sputtering, Surface \& Coatings Technology 86-7 (1-3) (1996) 640-647.

[20] P. Nayar, A. Khanna, D. Kabiraj, S.R. Abhilash, B.D. Beake, Y. Losset, B. Chen, Structural, optical and mechanical properties of amorphous and crystalline alumina thin films, Thin Solid Films 568 (2014) 19-24.

[21] P.V. Patil, D.M. Bendale, R.K. Puri, V. Puri, Refractive index and adhesion of $\mathrm{Al}_{2} \mathrm{O}_{3}$ thin films obtained from different processes - A comparative study, Thin Solid Films 288 (1-2) (1996) $120-124$.

[22] K.S. Shamala, L.C.S. Murthy, K.N. Rao, Studies on optical and dielectric properties of $\mathrm{Al}_{2} \mathrm{O}_{3}$ thin films prepared by electron beam evaporation and spray pyrolysis method, Mater. Sci. Eng. B-Solid State Mater. Adv. Technol. 106 (3) (2004) 269-274.

[23] J. Gottmann, A. Husmann, T. Klotzbucher, E.W. Kreutz, Optical properties of alumina and zirconia thin films grown by pulsed laser deposition, Surface \& Coatings Technology 100 (1-3) (1998) 415-419.

[24] J. Gottmann, E.W. Kreutz, Pulsed laser deposition of alumina and zirconia thin films on polymers and glass as optical and protective coatings, Surface \& Coatings Technology 116 (1999) 1189-1194.

[25] A. Pillonnet, C. Garapon, C. Champeaux, C. Bovier, R. Brenier, H. Jaffrezic, J. Mugnier, Influence of oxygen pressure on structural and optical properties of $\mathrm{Al}_{2} \mathrm{O}_{3}$ optical waveguides prepared by pulsed laser deposition, Appl. Phys. A-Mater. Sci. Process. 69 (1999) S735-S738. [26] F. Di Fonzo, D. Tonini, A.L. Bassi, C.S. Casari, M.G. Beghi, C.E. Bottani, D. Gastaldi, P. Vena, R. Contro, Growth regimes in pulsed laser deposition of aluminum oxide films, Appl. Phys. A-Mater. Sci. Process. 93 (3) (2008) 765-769. 
[27] S. Choopun, H. Tabata, T. Kawai, Self-assembly ZnO nanorods by pulsed laser deposition under argon atmosphere, Journal of Crystal Growth 274 (1-2) (2005) 167-172.

[28] R. Eason, Pulsed laser deposition of thin films applications-led growth of functional materials, Wiley-Interscience A John Wiley \& Sons, Inc., Publication, 2007.

[29] D.W. Thompson, P.G. Snyder, L. Castro, L. Yan, P. Kaipa, J.A. Woollam, Optical characterization of porous alumina from vacuum ultraviolet to midinfrared, J. Appl. Phys. 97 (11) (2005) 113511.

[30] K. Kaminska, A. Amassian, L. Martinu, K. Robbie, Growth of vacuum evaporated ultraporous silicon studied with spectroscopic ellipsometry and scanning electron microscopy, J. Appl. Phys. 97 (1) (2005) 013511.

[31] X.C. Zeng, D.J. Bergman, P.M. Hui, D. Stroud, Effective-medium theory for weakly nonlinear composites, Phys. Rev. B 38 (15) (1988) 10970-10973.

[32] D.M. Mattox, Handbook of Physical Vapor Deposition (PVD) Processing (Second Edition), William Andrew Publishing, Oxford, 2010.

[33] J. Kischkat, S. Peters, B. Gruska, M. Semtsiv, M. Chashnikova, M. Klinkmueller, O. Fedosenko, S. Machulik, A. Aleksandrova, G. Monastyrskyi, Y. Flores, W.T. Masselink, Midinfrared optical properties of thin films of aluminum oxide, titanium dioxide, silicon dioxide, aluminum nitride, and silicon nitride, Applied Optics 51 (28) (2012) 6789-6798.

[34] E.D. Palik, Handbook of Optical Constants of Solids, Academic Press, San Diego CA, USA, 1997. 


\section{Figure captions}

Fig. 1. XRD patterns of alumina films deposited under vacuum, $5 \times 10^{-4} \mathrm{mbar}$, and $5 \times 10^{-2} \mathrm{mbar}$ of Ar.

Fig. 2. Evolution of the alumina thin films refractive index $\left(n \mathrm{Al}_{2} \mathrm{O}_{3}\right)$, their effective refractive index ( $n$ effective), and the void content estimated by BEMA (\%) depending on the thickness of the films determined by VASE. Note that the curves guide the eyes.

Fig. 3. AFM images of alumina films deposited under various background atmospheres - (a) vacuum $\left(4.5 \times 10^{-6} \mathrm{mbar}\right)-$ (b) $5 \times 10^{-4} \mathrm{mbar}$ of $\mathrm{Ar}-$ (c) $5 \times 10^{-2} \mathrm{mbar}$ of $\mathrm{Ar}$.

Fig. 4. Spectral dependences of refractive index of alumina thin films fabricated under vacuum and two different Ar pressures compared to already published data $[33,34]$. 


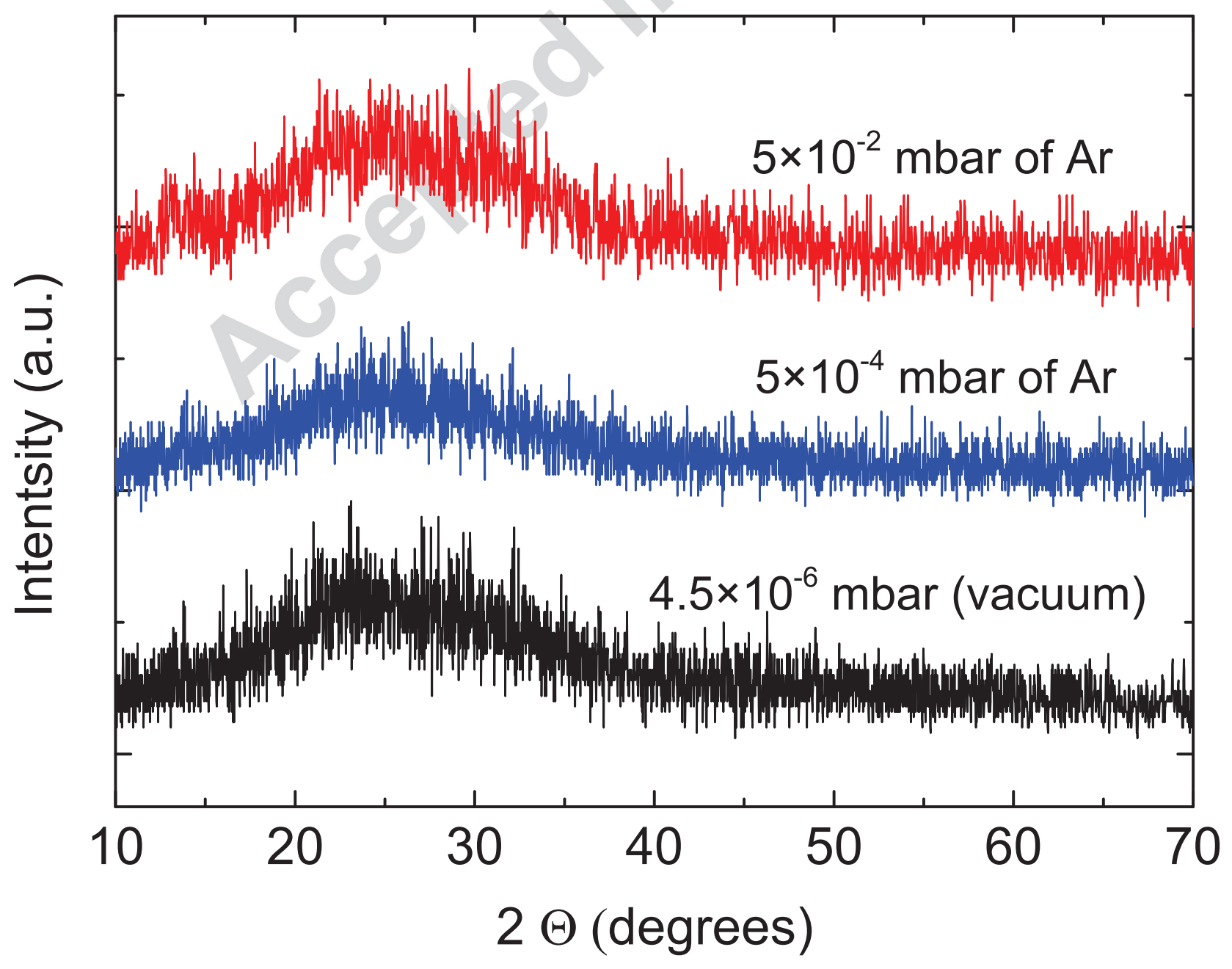




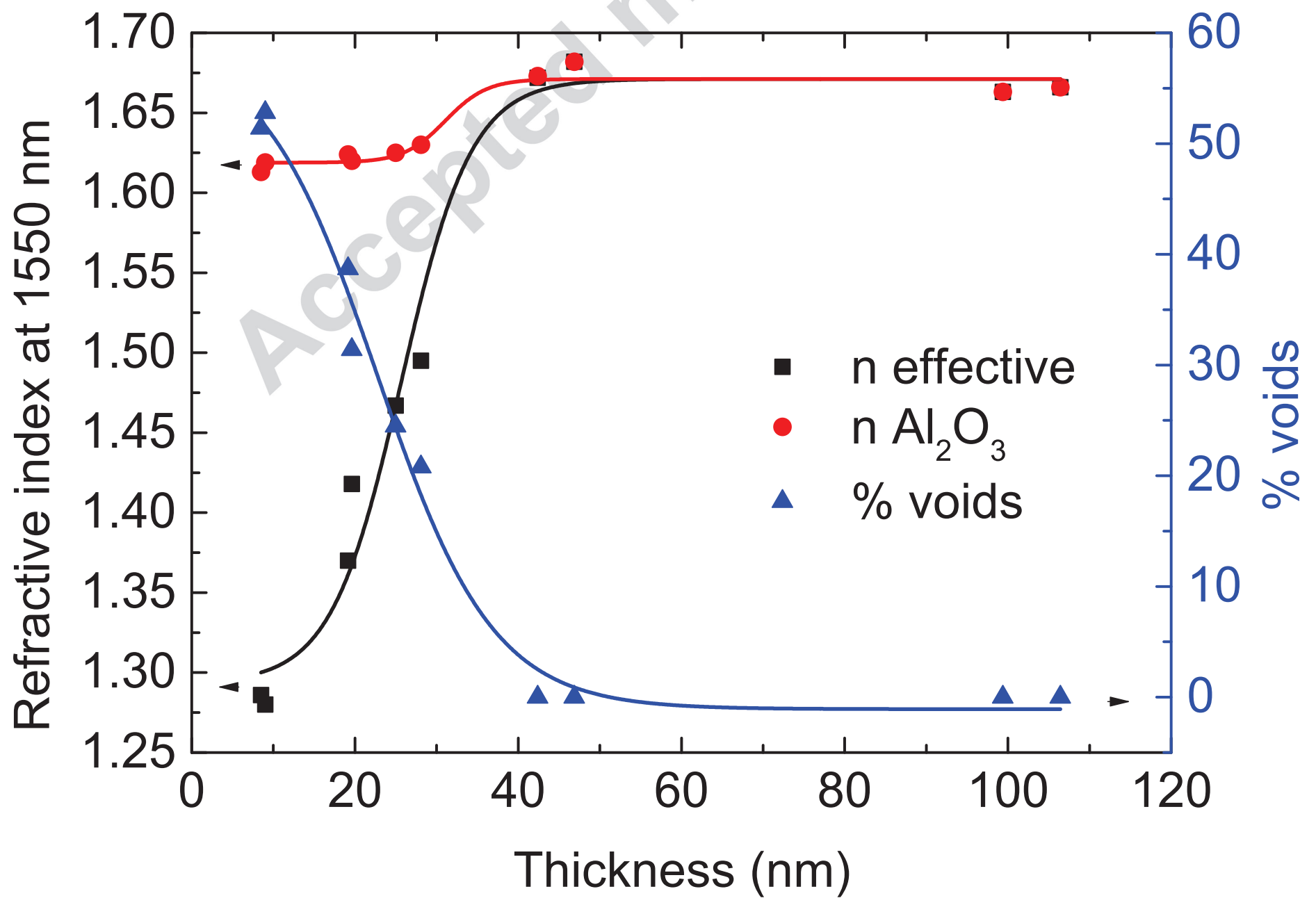



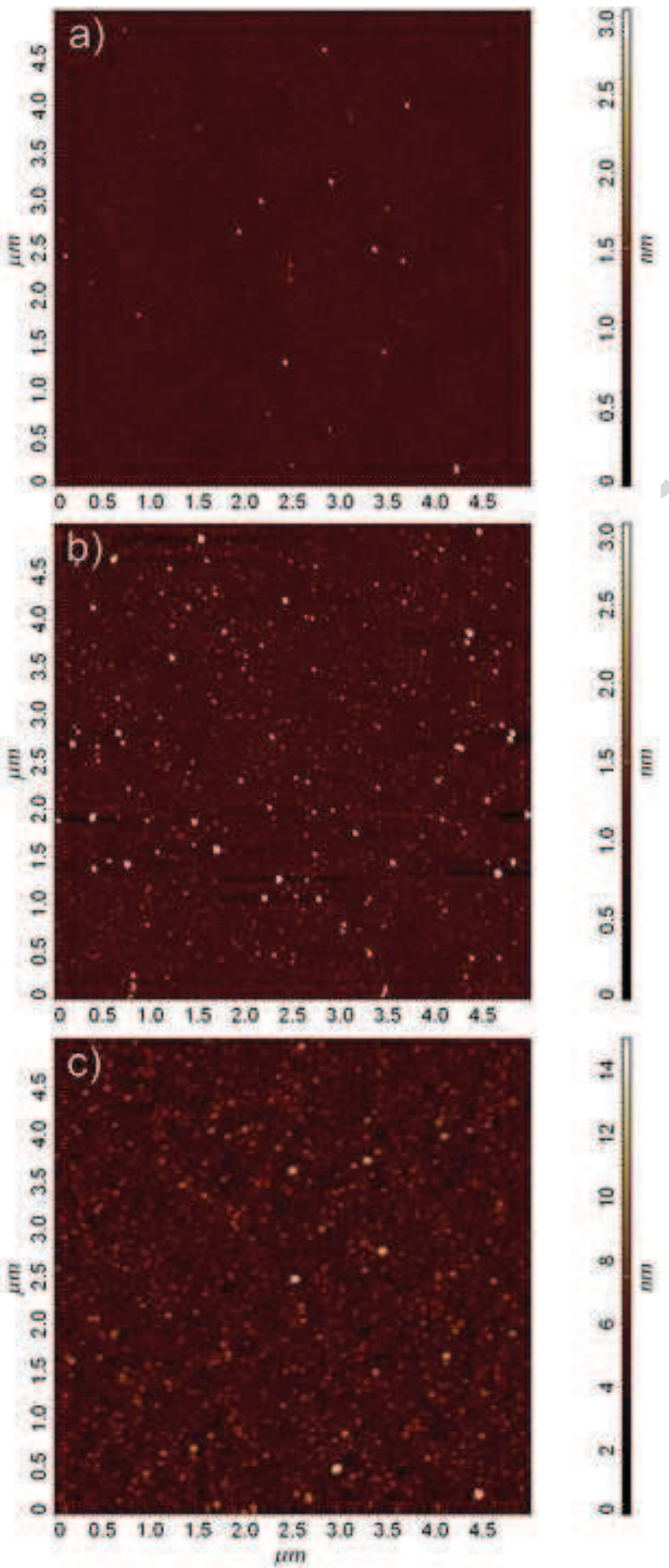


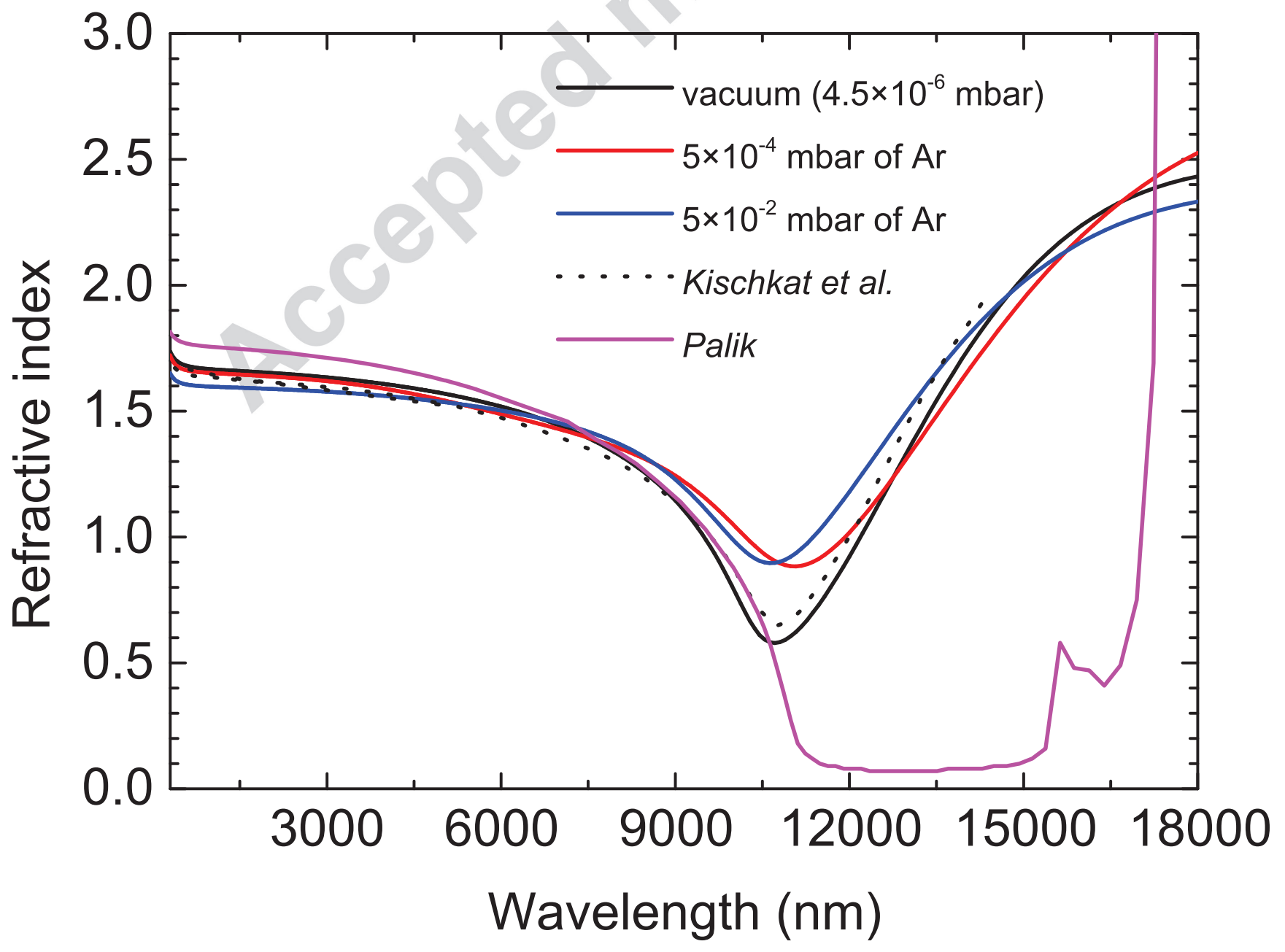

